\title{
Fulminant hepatic failure in association with quetiapine: a case report
}

\author{
Fawaz Al Mutairi ${ }^{1}$, Girish Dwivedi ${ }^{1}$ and Turki Al Ameel ${ }^{2^{*}}$
}

\begin{abstract}
Introduction: Fulminant hepatic failure is a serious disease with significant mortality and morbidity. Identifying the exact cause of hepatic failure and predicting prognosis is of paramount importance in managing such patients. Drug-induced liver injury is a common but challenging entity to treat. The use of newer drugs and medications with previously unknown hepatotoxicity add to the challenges faced by treating physicians. Quetiapine is an antipsychotic that has rarely been linked to acute liver injury. In the present work we describe a case of fulminant hepatic failure secondary to use of quetiapine.
\end{abstract}

Case presentation: A 59-year-old Caucasian woman with known Parkinson's disease was being treated with quetiapine for hallucinations. She was referred to our hospital with yellow discoloration of the sclera and later on developed clinical features suggestive of hepatic encephalopathy. A diagnosis of fulminant hepatic failure was made following her admission to the intensive care unit. Her condition improved after discontinuing the drug and providing the standard supportive treatment.

Conclusions: Our findings in the present report emphasize the importance of keeping an open mind in cases of fulminant hepatic failure. As drug-induced hepatotoxicity is the most common cause of fulminant hepatic failure in many parts of the world, consideration should be given to the medication(s) patients receive as the potential cause and a review of this list should be part of the clinical care given.

Keywords: Acute liver injury, Fulminant hepatic failure, Quetiapine

\section{Introduction}

Fulminant hepatic failure (FHF) is defined by the rapid development of severe acute liver injury accompanied by synthetic dysfunction and the development of encephalopathy in an individual with either a previously normal liver or well compensated liver disease [1,2]. Proposed definitions of the time course for fulminant hepatic failure include the development of encephalopathy within eight weeks of the onset of symptoms in a patient with a previously healthy liver [1] or the appearance of encephalopathy within two weeks of developing jaundice, in a patient with or without previous underlying liver dysfunction [2]. Although, FHF can result from a wide variety of causes, drug-induced hepatoxicity is common, causing high mortality with an estimated 3.5 deaths per million people in the US alone [3]. The reported short-term survival is $49 \%$

\footnotetext{
* Correspondence: talameel@gmail.com

${ }^{2}$ Division of Gastroenterology, University of Alberta, Edmonton, Alberta, Canada

Full list of author information is available at the end of the article
}

although the outcome of FHF has significantly improved with the introduction of liver transplantation [4].

Quetiapine (Seroquel $^{\circledR}$; AstraZeneca) is an atypical antipsychotic agent used to control positive and negative symptoms in patients with psychosis [5]. It has a low side effect profile and is generally well tolerated in doses from 150 to $750 \mathrm{mg} /$ day [6]. The common known side effects of quetiapine include a mild asymptomatic disturbance of liver enzymes, leukopenia, pancytopenia and thrombotic thrombocytopenic purpura $[7,8]$. Rarely, neuroleptic malignant syndrome, hyperprolactinemia, myoclonus and cardiac arrhythmias have also been reported as adverse effects [9-12]. We describe the case of a patient with FHF caused by quetiapine, a rarely reported adverse effect of this drug associated with significant mortality if not identified and treated early [13-15].

\section{Case presentation}

A 59-year-old Caucasian woman with a prior history of Parkinson's disease was on carbidopa-levodopa

\section{Biomed Central}


combination for three years and oxazepam along with pramipexole for six months before she developed hallucinations that were attributed to pramipexole therapy. Subsequently, pramipexole was discontinued and our patient was given quetiapine to treat her hallucinations. She had received six weeks of quetiapine therapy before presenting to our hospital with the main complaint of feeling unwell for three weeks. Her symptoms were accompanied with nausea, vomiting, decrease appetite and abdominal pain for a few days duration. She had also noticed a yellowish discoloration of her sclera but no change in the color of urine or stool. There was no accompanying history of fever, chills or rigors. No risk factors or history suggestive of familial liver disease was provided. She was a non-smoker and denied drinking alcohol.

The results of a general physical examination revealed a stable hemodynamic status with bilateral icterus but no pallor, cyanosis or lymphadenopathy. An abdominal examination demonstrated distention with tenderness in the right upper quadrant but no clinically detectable ascites or hepatosplenomegaly. No other stigmata of chronic liver disease were seen. Cardiovascular and respiratory system examinations were unremarkable. No abnormality was detected on the neurological examination.

Admission blood test results showed a normal hemogram and normal renal function tests including electrolytes but deranged liver function tests (alanine aminotransferase: 71IU/L; aspartate aminotransferase: 740IU/L; lactate dehydrogenase: 737IU/L; $\gamma$-glutamyl transferase: 509IU/L; alkaline phosphatase: $196 \mathrm{IU} / \mathrm{L}$; total bilirubin: $244 \mu \mathrm{mol} / \mathrm{L}$ and an international normalized ratio (INR) of 2.7). Her blood ethanol level was in the normal range. Viral serology test results for hepatitis A, B and C were negative. A vasculitic screen was performed, which revealed an anti-nuclear antibody titer of 1:1600 and positive anti-double-stranded deoxyribonucleic acid (dsDNA) results, but negative results for anti-liver kidney microsomal antibody. Tests for anti-neutrophil cytoplasmic antibodies showed negative results for anti-myeloperoxidase but were equivocal for anti-proteinase 3 . Normal $\alpha-1$ anti-trypsin levels $(1.89 \mu \mathrm{mol} / \mathrm{L})$ and normal levels for other immunoglobulins were found (IgG: $34 \mathrm{~g} / \mathrm{L}$, IgA: $2.44 \mathrm{~g} / \mathrm{L}$ and $\operatorname{IgM}: 1.5 \mathrm{~g} / \mathrm{L}$ ). The results of screening tests for Wilson's disease and hemochromatosis were also negative.

An ultrasound scan of the abdomen showed a distended gall bladder with absence of stones and no free fluid in the abdomen. The liver and spleen sizes were reported as within normal ranges. Computerized tomography of the abdomen confirmed the absence of intra-hepatic biliary dilatation.

In view of the above-mentioned findings and her history, our patient was admitted with a probable diagnosis of quetiapine-induced hepatitis. Quetiapine was discontinued but other medications, that is, carbidopa-levodopa and oxazepam, were not stopped. The initial treatment was mainly supportive. However, within 48 hours of admission, our patient demonstrated signs of encephalopathy in the form of confusion, astrexis and impaired level of consciousness with the development of significant ascitis. She was subsequently transferred to the intensive care unit and the local liver transplant team was consulted for probable transplant. After ruling out spontaneous bacterial peritonitis, our patient was treated with lactulose, spironolactone and furosemide. She was also given methyprednisolone 20mg intravenously. A follow-up abdominal ultrasound scan revealed splenomegaly, coarse liver parenchyma and ascitis but no focal lesions or cholelithiasis. The hepatic and portal circulations were patent on Doppler examination. A trans-jugular liver biopsy confirmed extensive confluent and bridging necrosis predominantly in zone 3 . The portal area contained mild to focally moderate mixed inflammatory cellular infiltrate consisting of lymphocytes, macrophages, eosinophils and a few polymorphonuclear cells along the boundaries of the necrotic areas. The parenchyma showed variable degrees of hepatocellular degeneration and mild mixed inflammatory cellular infiltrate consisting mainly of lymphocyes and macrophages with few plasma cells and prominent Kupffer cells. The overall histopathological picture was reported to be suggestive of an acute hepatitis with confluent and bridging necrosis, indicative of drug-induced liver injury.

Our patient's clinical symptoms improved gradually accompanied by improvement in biochemical parameters over the course of her stay in the intensive care unit. The encephalopathy resolved completely with improvement in icterus, nutritional status and oral intake. Later on, she was transferred out of the intensive care unit to the general ward and put on a tapering dose of oral prednisolone starting at $40 \mathrm{mg} /$ day.

She was discharged home in a stable condition approximately six weeks after the initial admission on $20 \mathrm{mg}$ prednisolone per day with a suggested tapering of $5 \mathrm{mg}$ every week. She was advised against taking quetiapine in the future. Follow-up blood test results eight weeks after discharge revealed mildly elevated liver enzymes (less than twice the upper limit of normal) with normal synthetic and excretory hepatic functions.

\section{Discussion}

Quetiapine is a dibenzothiazepine, an atypical antipsychotic agent that is known to have a positive effect on positive and negative symptoms of psychosis [5]. Although its mechanism of action is poorly understood, it is thought to exert its effect through a combination of dopamine (D2) and 5-hydroxytryptamine-2 (5HT2) receptor antagonism. Quetaipine demonstrates a heterogenic antagonist activity 
in the brain with stronger antagonism of $5 \mathrm{HT} 2$ receptors compared to D2. It also has affinities for a range of other neurotransmitter receptors such as serotonin 5HT1a, D1, histamine- 1 and adrenergic $\alpha-1$ and $\alpha-2$. It has, however, no appreciable affinities for cholinergic muscarinic and benzodiazepine receptors [16]. It is metabolized via the hepatic mixed function oxidase system using the cytochrome P450 3A4 isoenzyme [5]. Quetiapine [17] was considered to be a non-hepatotoxic drug except for a mild and transient asymptomatic elevation of liver enzymes prior to the first published report of quetiapine-induced FHF by El Hajj et al. in 2004 [13].

The most likely etiology in our patient's case was quetiapine-induced liver injury. Other possible etiologies such as viral hepatitis $\mathrm{A}, \mathrm{B}$ and $\mathrm{C}$, metabolic disorders including Wilson's disease and vascular diseases such as Budd-Chiari syndrome were ruled out. The other diagnosis considered with such a presentation is 'FHF of unknown etiology', which accounts for $17 \%$ of FHF cases [18]. However, the temporal association between the commencement of the medication and the onset of her symptoms strongly indicates the possibility of quetiapine as the culprit agent. The other differential diagnosis that was considered was of autoimmune hepatitis due to the elevated anti-nuclear antibody level found in our patient. However, anti-nuclear antibody elevation is a nonspecific finding and can also be seen in drug-induced hepatic injury. Moreover, in absence of other serological markers and absence of findings on liver biopsy, an autoimmune etiology is very unlikely. Of note, acute liver injury secondary to autoimmune process or drug toxicity shows response to steroid therapy in both cases. Also, extensive zone 3 predominant necrosis (as seen in our patient) on liver biopsy is seen in drug-induced liver injury [19]. Indeed, on the Roussel Ucalf Causality Assessment Method/ Council for International Organizations of Medical Sciences scoring system our patient had a score of 7 , indicating probable causation of FHF by quetiapine [20,21].

In cases of FHF, the decision for liver transplantation is based on clinical judgment and utilization of prognostic criteria such as the King's College criteria. For known acetaminophen-induced FHF, the criteria include: disease etiology (cryptogenic/toxin), age ( $<10$ years, $>40$ years), duration of jaundice (more than one week before the development of encephalopathy), serum bilirubin concentration of $18 \mathrm{mg} / \mathrm{dl}$ and INR $>3.5$, our patient fulfilled only three of these five criteria [22]. Complete resolution except for minimal elevation of liver enzymes was the final outcome in our patient as opposed to mortality in two other cases of quetiapine-induced liver injury reported in the literature [13]. One other case reported by Shpaner et al. showed improvement after quetiapine cessation, which may have been due to subfulminant rather than fulminant hepatic failure [15].

\section{Conclusions}

Our patient's case emphasizes the importance of keeping an open mind in cases of fulminant hepatic failure. As drug-induced hepatotoxicity is the most common cause of fulminant hepatic failure in many parts of the world, consideration should be given to the medication(s) patients receive as being the potential cause, and a review of the list should be part of the clinical care administered.

\section{Consent}

Written informed consent was obtained from the patient for publication of this case report and any accompanying images. A copy of the written consent is available for review by the Editor-in-Chief of this journal.

Competing interests

The authors declare that they have no competing interests.

\section{Authors' contributions}

FA: Designed the study, reviewed the literature and drafted the first manuscript. GD: Reviewed and edited the manuscript. TA: Reviewed the literature, reviewed and edited the manuscript. All authors read and approved the final manuscript.

\section{Author details}

${ }^{1}$ University of Ottawa Heart Institute, Ottawa, Ontario, Canada. ${ }^{2}$ Division of Gastroenterology, University of Alberta, Edmonton, Alberta, Canada.

Received: 21 March 2012 Accepted: 4 November 2012

Published: 12 December 2012

\section{References}

1. Trey C, Davidson LS: The management of fulminant hepatic failure. In Prognosis in Liver Disease. Edited by Popper H, Shaffiner F. New York, NY: Grune and Stratton; 1970:282.

2. Bernauau J, Reuff B, Benhamou JP: Fulminant and subfulminant liver failure: definitions and causes. Semin Liver Dis 1986, 6:97.

3. Hoofnagle JH, Carithers RL Jr, Shapiro C, Ascher N: Fulminant hepatic failure: summary of a workshop. Hepatology 1995, 21:240-252.

4. Schiodt FV, Atillasoy E, Shakil AO, Schiff ER, Caldwell C, Kowdley KV, Stribling R, Crippin JS, Flamm S, Somberg KA, Rosen H, McCashland TM, Hay JE, Lee WM: Etiology and outcome for 295 patients with acute liver failure in the United States. Liver Transp/ Surg 1999, 5:29-34.

5. Lacy C, Armstrong L, Goldman M, Lance L: Quetiapine. In Drug Information Handbook. 9th edition. Hudson, OH: Lexi-comp Inc; 2001:1046-1047.

6. Mullen J, Jibson MD, Sweitzer D: A comparison of the relative safety, efficacy, and tolerability of quetiapine and risperidone in outpatients with schizophrenia and other psychotic disorders: the quetiapine experience with safety and tolerability (QUEST) study. Clin Ther 2001, 23:1839-1854.

7. Iraqi A: A case report of pancytopenia with quetiapine use. Am J Geriatr Psychiatry 2003, 11:694

8. Huynh M, Chee K, Lau DH: Thrombotic thrombocytopenic purpura associated with quetiapine. Ann Pharmacother 2005, 39:1346-1348.

9. Bourgeois JA, Babine S, Meyerovich M, Doyle J: A case of neuroleptic malignant syndrome with quetiapine. J Neuropsychiatry Clin Neurosci 2002, 14:87.

10. Alexiadis M, Whitehorn D, Woodley $H$, Kopala L: Prolactin elevation with quetiapine. Am J Psychiatry 2002, 159:1608-1609.

11. Velayudhan L, Kirchner V: Quetiapine-induced myoclonus. Int Clin Psychopharmacol 2005, 20:119-120.

12. Gajwani P, Pozuelo L, Tesar GE: QT interval prolongation associated with quetiapine (Seroquel) overdose. Psychosomatics 2000, 41:63-65.

13. El Hajj I, Sharara Al, Rockey DC: Subfulminant liver failure associated with quetiapine. Eur J Gastroenterol Hepatol 2004, 16:1415-1418. 
14. Naharci Ml, Karadurmus N, Demir O, Bozoglu E, Ak M, Doruk H: Fatal hepatotoxicity in an elderly patient receiving low-dose quetiapine. Am J Psychiatry 2011, 168:212-213.

15. Shpaner A, Li W, Ankoma-Sey V, Botero RC: Drug-induced liver injury: hepatotoxicity of quetiapine revisited. Eur J Gastroenterol Hepatol 2008, 20:1106-1109.

16. McConville BJ, Arvanitis LA, Thyrum PT, Yeh C, Wilkinson LA, Chaney RO, Foster KD, Sorter MT, Friedman LM, Brown KL, Heubi JE: Pharmacokinetics, tolerability, and clinical effectiveness of quetiapine fumarate: an openlabel trial in adolescents with psychotic disorders. J Clin Psychiatry 2000, 61:252-260

17. Zeneca Pharma Ltd: Quetiapine (seroquel). Product monograph. London, UK Zeneca; 1998:1-25.

18. Ostapowicz G, Fontana RJ, Schiødt FV, Larson A, Davern TJ, Han SH, McCashland TM, Shakil AO, Hay JE, Hynan L, Crippin JS, Blei AT, Samuel G, Reisch J, Lee WM, US Acute Liver Failure Study Group: Results of a prospective study of acute liver failure at 17 tertiary care centers in the United States. Ann Intern Med 2002, 137:947-954.

19. Bénichou C: Criteria of drug-induced liver disorders. Report of an international consensus meeting. J Hepatol 1990, 11:272-276.

20. Larrey D: Epidemiology and individual susceptibility to adverse drug reactions affecting the liver. Semin Liver Dis 2002, 22:145-155.

21. Danan $G$, Benichou C: Causality assessment of adverse reactions to drugs-I. A novel method based on the conclusions of international consensus meetings: application to drug-induced liver injuries. J Clin Epidemiol 1993, 46:1323-1330

22. O'Grady JG, Alexander GJ, Hayllar KM, Williams R: Early indicators of prognosis in fulminant hepatic failure. Gastroenterology 1989, 97:439-445.

doi:10.1186/1752-1947-6-418

Cite this article as: Al Mutairi et al:: Fulminant hepatic failure in association with quetiapine: a case report. Journal of Medical Case Reports

\section{Submit your next manuscript to BioMed Central and take full advantage of:}

- Convenient online submission

- Thorough peer review

- No space constraints or color figure charges

- Immediate publication on acceptance

- Inclusion in PubMed, CAS, Scopus and Google Scholar

- Research which is freely available for redistribution 